\title{
An Action Research of English Songwriting Implementation in Teaching English as a Second Language for University Students
}

\author{
Shu-Chin Su, ${ }^{1, *}$, Tang Ling ${ }^{2}$ \\ ${ }^{1}$ Department of English, the Tamsui Campus of Aletheia University, Taiwan \\ ${ }^{2}$ School of Economics and Trade, Guangdong University of Foreign Studies, China
}

Copyright $(\mathrm{O} 2018$ by authors, all rights reserved. Authors agree that this article remains permanently open access under the terms of the Creative Commons Attribution License 4.0 International License

\begin{abstract}
This research aimed to investigate whether the implementation of "English Songwriting" as a teaching activity could increase students' learning attitudes. The researcher noted the challenges while the research was carried out and provided solutions for the study. Action research was conducted with 110 students from a private university in Taiwan as participants. It spanned for two semesters with two instances of English songwriting activities.[1] Data collection instruments included both the students' reflections and their levels of satisfaction toward the English songwriting activities before, during, and after teaching. Qualitative methodology was used to analyze whether English songwriting was able to improve the students' attitudes on English learning through their opinions, feedback, interviews and satisfaction questionnaires. The findings showed that all of the students completed the task of English Songwriting, and most of the students did the work in a joyful and serious manner. Results showed that this activity increased students' English vocabulary and motivation for learning. Other abilities also developed such as teamwork, communication, appreciation of peers' talents in writing lyrics and songs, brainstorming, creativity and research work. The contents of the songwriting could also be a first step to have a better understanding of students' psychological and emotional status. The researcher provided suggestions for English teaching and recommendations for future studies based on the results.
\end{abstract}

Keywords English Songwriting, Action Research

\section{Introduction}

Action research was used in this study by first identifying the problem. Based on the researcher's 20 -year teaching experience and classroom observations, she found that the students in this private university possessed passive learning attitudes and were fond of traditional teaching methods; they did not welcome the concept of "flipped classroom or flipped learning".[2] Most students preferred receiving more technical lessons taught or provided by teachers. Students were neither attentive to the lectures nor focused on the teachers' explanations. Most unfortunate was that they seldom turned in their homework/assignment or accessed the online teaching materials on the teacher's homepage. Moreover, students did not like to respond to teachers' questions during the classes. It was relatively normal to see students not raising hands or having no comments/opinions whenever a question was raised.

Since students did not like to do any extra assignments, they were strongly against the idea of making "presentations." They usually did not prepare for their presentations, tended to be in a muddle, and were already satisfied receiving passing grades from teachers. During class, they spent most of their time using smartphones; they did not even lift their heads up to pay attention to the teachers; they did not do any of the textbook exercises or jot anything down in class. In other words, they seemed to avoid making any effort while expecting to get passing grades. However, there is a wide range of suggested solutions to address the apparent insufficiencies in the current educational situation (McLaughlin, Roth, Glatt, Gharkholonarehe, Davidson, Griffin, Esserman, \& Mumper, 2014)[3]. The second step in action research is developing a plan. This is a new pedagogical method has emerged that employs video/screencast/podcast lectures as formative and summative homework, and it can be used to facilitate active, group-based problem solving activities in the classroom (Bishop \& Verleger, 2013; Milman, 2012). [4] Relatively, they preferred "student-centered" learning activities.

McLaughlin et al. (McLaughlin et al., 2014) pointed out that educators have to rethink the traditional concepts of in-class, lecture-based, and teacher-centered course model. 
Vice versa, the flipped classroom method is designed for students to learn by themselves, and is dedicated to engage students in student-centered activities during their study time. It was recommended that teachers should design activities in class to promote academic motivation. One of these was "English songwriting," which the researcher implemented in class as well as engaged herself into the study.

Students were expected to involve themselves in the activity, put aside their smartphones, and to interact with their peers. In order to maintain a creative environment for them as well as to prevent them from committing plagiarism, a great deal of effort of explanation/definition was required. In order to attain the objectives, not only did obstacles have to be solved, but innovative teaching approaches also had to be generated. Third step in action research is implementing the plan. "Globalization" opens a world of opportunities for Taiwanese nationals to communicate with English-speaking foreigners. Hence, English proficiency has become more important now than ever. More and more teachers are dissatisfied with the minimal effect of adopting the traditional grammar-translation method. To facilitate students' academic motivation and to improve their English proficiency, classroom teachers must be able to design practical and interesting courses.

"Songs" are often used as a medium in language learning. Songs bring a cheerful atmosphere into the classroom and thus changes the conventional teaching routine. It plays a big part in learning new words, pronunciation, sentence structures, and sentence patterns. Hence, it has the advantage of fostering students' integrated capacity by teaching English songs as a supplementary approach, and using it as a tool of "creativity" to elevate their interest in English learning. Furthermore, it is effective to facilitate their English proficiency (Richards, 1969) [5].

"Song is a particular literature genre, not only has it a unique form and connotation" (Si \& Sun, 2007, p. 92) [6], but it also includes literature and music to help students' understanding of art. Through variety of lyric and melody of music, student's capacity of appreciation from different aspects is cultivated (Lin, 2008).[7] Songwriting in Mandarin, Taiwanese, and Hakka languages is popular in Taiwan; however, it is rarely used in English teaching. To properly translate English songs is difficult; subsequently, to write them is even much more challenging. Since it is encouraged to be creative in teaching, it is necessary to make a bold attempt of conducting an English songwriting activity. The outcome will be known only after doing such experiment. For this strategy to be effective in linking the activity to English learning, the connotation of impossibility must be removed first. Although some teachers presently use English songs in their class, songwriting is rarely seen.

This study suggests starting with translation of Chinese song lyrics into English, or rewriting the lyrics of students' favorite English melodies. Gradually, confidence will build up and help students polish their writing skills through song translation. This may help students become more and more willing to accept the task of writing an English song. In English songwriting, poetic quality and achievability complement each other, producing dual aesthetic value, which bring up a manifest effect on liberal education, aesthetic discipline, and students' spiritual development.

Owing to the fact that not every student can be sophisticated songwriters, teachers have to show more tolerance when submitted works are not up to par. Before achieving a delicate production, it has to be a rigid production first. If the study proves to be able to facilitate students' academic motivation or if its impact is studied thoroughly, it will benefit the English "featured teaching" approach. Through cooperative learning, students are divided into groups to work on a common objective and are motivated to help others learn various academic contents.

Many researches revealed that the structure of "cooperative learning" approach, in certain specific conditions, could enhance students' academic performance in most of the subjects or grade scores. Though the structure of "cooperative learning" approach was proved to be effective, it was not applied on many instances (Slavin, et al., 2012). [8] The researcher interpreted the application of "English songwriting" to have students learn English in a cheerful atmosphere - the concept of "learning by doing," probing the practices where students initially translated Chinese lyrics and melodies into English, then continued to create their own English songs.

In particular, teachers should be able to distinguish creation/original from translation. Creation/original means "the act of starting something for the first time". So when students create a song, they should write the melody and the lyric without consulting other songs. A translated version implies that "a recording of a song that was first recorded or made popular by somebody else". Concerning the limit of student's English language proficiency and music accomplishment, translated versions were deemed acceptable in this study. Students were allowed to translate songs or adapt songs for this songwriting activity. Fourth and final step in action research is observing, reflecting and sharing. This study uses participant observation to accomplish this step. It is defined as the use of a scientific process and particular instrument to systematically observe and record the behaviors and phenomenon of the observed participants.[9] The researcher, as a teacher, observed students' behavior in the class directly and recorded it systematically. In addition, these observations together with students' reflections will be shared to highlight how the findings relate or contribute to English learning.

\section{Literature Review}

Many studies indicated that English songs are 
beneficial to English learning. Through an arts intervention study, Ludke initially found empirical evidence for a significant benefit of learning material in foreign language learning through arts activities. Furthermore, by means of the comparative study, Ludke indicated that songs and singing activities have greater (and more significant) benefits in foreign language learning than visual art and drama activities (Ludke, 2016). [10]

\subsection{The Benefits of Using English Songs}

\subsubsection{English Songs Can be Used as Subsidiary}

Motivation is thought as one of the most important factors to the success of second language acquisition (Xing, 2017). [11] As a subsidiary, English songs can create an active classroom as well as a strong motivation for English learning. Young people are linked closely with popular culture, which includes popular music. Cheung claimed that popular culture can enhance the interest of students' learning and the relaxing atmosphere in class, which can help them study English better. Cheung suggested that teachers should record their students' interests and consider these when making strategies or selecting materials for the class (Chenug 2001). [12] As for older English learners, they did not like learning English with pressure or examinations. They preferred more entertaining and relaxing classes. English songs change the routine of classroom activities (Chuang, 2011). [13] In vocational school, most students were not interested in learning English. Using English songs in the classroom can create an active and real environment of English learning that can help increase their interest in the language (Shao, 2005). [14]

\subsubsection{English Song Can be Used as a Teaching Tool}

As a teaching tool, English songs can assist in honing different English skills. Generally, English skills are classified into the tasks of listening, speaking, reading and writing. Particularly, learners can test our English skills in areas such as comprehension, pronunciation, grammar, impromptu speaking, ability to summarize, and formal and informal writing. If teachers want to manage our learning process better and make a significant progress, they should break it down into three steps-from awareness to priorities to action (Bertoldi, Kollar \& Ricard, 1988). [15]

Zhou looked into the combination of using senior high school English vocabulary and multiple English songs to enhance the ability of students to remember the words. Zhou concluded that the songs not only helped them in vocabulary retention but also in grammar comprehension (Zhou, 2011). [16] Phrasal verbs are always considered the most difficult part for second language learners. Some researchers used the corpus of the study to compare four music genres (Pop, Rock, Metal and Hip pop) to find which include more "useful" phrasal verbs. Moreover, they indicated that learners' interest should first be considered when teachers use music in the class (Akbary, Shahriari \& Fatemi, 2016). [17] Even native English speakers claim that compound words are an area of difficulty when they are Emergent Readers. Fortunately, music can promote literacy in Phonological awareness, Phonemic awareness and Orthographic awareness (Middleton, 2012). Middleton (Middleton, 2012) created useful modules which can help learners in different grade levels promote literacy as a useful tool for regular classroom teachers. [18]

Listening comprehension can be further developed when practicing the skill with English songs in class. This is because students are exposed to more vocabulary and sentence patterns when listening and singing songs, which can improve their English proficiency (Jia, 2012). [19] As for the English-major students in the university, listening skills should also be exercised regularly. English songs may not improve their innovation; however, it promotes their learning interests and consequently helps with increasing (Jiang, 2015). [20]

When someone learns English as a second language, may focus more on the listening, words and spoken English. In the English-speaking countries, they may have a higher requirement of the use of English. Duggan examined the uses of music in high school English/language arts classes in South Dakota. He found that the most successful use is to enhance the comprehension of literature, which is followed by using music to energize student writings (Duggan, 2003). [21] The teacher is also an important factor in English song teaching. The relationship of the teacher and art can influence the teaching belief and classroom practices (McClain, 2006). [22] Nonetheless, when teachers use songs in English classes, it should be well incorporated with clear teaching and learning objectives (Chou, 2014).[23]

\subsection{Different English Songs across Various Cultures}

Every learner has his or her own cultural background. Harbon investigated Chinese learners specifically and confirmed that the choice of songs as learning material for Chinese learners should have two levels of meaning. The second level is that the students should be able to link it to a familiar Chinese goal for education (Harbon, 2008). [24] Many Chinese learners of the English language are confident in their reading skills but not in listening, speaking and writing skills. They want their teachers to concentrate more on developing these skills (Liu, Lin \& Wiley, 2016). English song is a useful tool to help teachers focus on cultivating these skills in the classroom. ${ }^{[25]}$ Liu researched the impact of English songs in the junior English teaching in China particularly and indicated that these have a unique function in the linguistics 
knowledge materials, cultural background materials and teaching background area. (Liu, 2012) [26]

Under the background of cross-culture, teaching a second language includes not only the language itself, but also the cultural meaning behind it. Wu confirmed that English songs can assist students in knowing the culture as well as in communicating with foreigners. (Wu, 2011) [27]

\subsection{English Songwriting in English Teaching}

English songwriting is another method in English teaching. It does not suffice to use English songs as teaching materials or play it as background music. Songwriting is influenced by many factors, such as the writer's background and perception. Hahn found that songwriters are willing to make and give meaning to songwriting (Hahn, 2015).[28] Some researches confirmed that students were able to establish a connection between their lives and the songwriting program, which was designed to influence character development (Justina Mei Yin So, 2012). [29]Even in kindergarten, it is important that teachers know the critical need of teaching songs to children in a thoroughgoing song-leading process (Liao \& Campbell, 2014).[30]

\subsection{The Disadvantage of Using English Songs}

However, some data still show that using songs is not the most helpful activity in English classes. Muñoz observed that when asked which type of English class activity allowed them to learn the most, only $3 \%$ of the students in Grade 3 and 5.1\% for Grade 6 chose songs. Majority of these young learners chose vocabulary as the most helpful activity instead (Muñoz, 2013). [31]

\subsection{Summary}

Many researches focus on English teaching in primary school and middle school, using English songs as teaching material and background music. Songwriting is too difficult for primary and middle school students. However, there has been no experiment on using English songwriting in teaching to university students. The purpose of this research was to probe the students' learning attitudes toward the implementation of English Songwriting in a private university. It is hypothesized that songwriting activity is beneficial to university students studying English.

\section{Method}

Action research was used in this study in the processes of collecting information as well as exploring topics of teaching, curriculum development, and students' behavior in the classroom. This method is done as follows:
(1) Observing individuals or groups: this is similar to multiple case researches signifying that the researcher collects data from several sources including individuals, families, groups or communities at the same time. [32] The researcher keeps the nature of the study in its natural condition instead of doing variable analysis. It allows the researcher to comprehend the whole study widely and deeply. Furthermore, observing society in its natural environment allows for unbiased findings. [33] In this study, data was collected from 55 students in two English classes across two semesters from February 2015 to February 2016. Full participant observation study means that the researcher or observer plays a similar role as those being observed. This way, members of the studied group are not aware of the researcher's identity and can thus, interact naturally. Partial participant observation study signifies that the researcher can totally participate in the study. In such method, the observer should inform the observed participants of his or her role. [33] This study used full participant observation method and the researcher took part as a teacher as well. The researcher interacted with the students as per usual and collected more information from students' behavior.

(2) Taking field notes: the researcher naturally observed the students during English class and made detailed notes while they were creating English songs. This way, the researcher was able to recognize whether or not English songwriting aided in learning.

(3) Using audio and video tape recording.

(4) Using structured and unstructured interviews. Structured interview entails that the researcher uses a series of preset and ordered questions to collect data. Unstructured interview, on the other hand, allows the researcher to proceed with questions without a standardized interview guide. [34] In this study, we used unstructured interviews and asked them about their feelings or suggestions toward the class.

(5) Distributing surveys or questionnaires: open-ended questionnaires do not require respondents or interviewees to choose from preset answers. When they know the intent of the questions, they can freely express their ideas in their own words. [32] In this study, we sent open-ended questionnaires to each student at the end of the term to ask them about their thoughts on English songwriting and encouraged them to answer it freely.

(6) using analytic documents (including memos and photography): this entails that the researcher applies original documentation to analyze and 
draw a conclusion. In this study, we collected students' lyrics and videos that they created in English class from March to September of 2014 to analyze their behaviors and to find out whether or not English songwriting has helped with their language learning. The data consisted of the lyrics and the videos of students' performances.

\section{Analysis and Discussion}

At the end of the semester, every group submitted an assignment, which included their videos, lyrics and their reflections of the study. These documents were very valuable data of our study. A considerable amount of information was collected from it, such as their emotions, their attitudes toward this homework and their comprehension of their lyric. It helped us identify the attitudes of students toward this assignment of songwriting activity. Students submitted 14 assignments including 14 videos, 14 lyrics and 21 responses. These songs from their assignments included 2 originals, 4 rifacimentos and 8 translations. These songs were coded as O1-O2, R1-R4 and T1-T7. It can be analyzed in three aspects: videos, lyrics and their feedback toward this assignment.

\subsection{Videos}

Many factors can be used for analysis from their videos such as the quality, tone of their songs, their art of singing, pronunciation and familiarity of their songs. Quality of the videos include clarity of picture and distinct of voices. Most of their videos had clear pictures and voices. If they recorded videos in an outdoor setting, it may have some noise in their videos but still manageable. There was one video, which was recorded on stage with a band. It was full of background noise and the researcher could not clearly listen to the singer's vocals. Most of them completed the assignment in a serious manner. It may mean that they either wanted to get a high grade or they were highly interested in this assignment.

Two originals had beautiful accompaniment; they played the guitar and recorded it in their homes. They also had beautiful voices and clear pronunciation. It was a joy to watch their videos. The researcher believed that they also enjoyed creating their songs. They were also familiar with their lyrics. It showed that they really learned and benefited from the assignment.

Four rifacimentos were very creative. It came in two forms. One was combining two English songs while the other was replacing the original lyrics of a song and sang it using the same tone. They totally showed their creativity in the videos. There were even moments of laughter in their videos. The researcher believed that the process-oriented mission they accomplished in this assignment was a great achievement and it really helped them learn English with high motivation.

Compared with the two methods above, eight translations were quite satisfactory. The group that chose to directly translate original lyrics had relatively more people. They used the original accompaniment from their smartphones when they recorded the videos. Some of them did not even have any accompaniment. The songs were always presented in chorus. However, this type of arrangement normally causes some other members of the group to be lazy. Some of them might just sing the songs during recording but did not do any other thing. Many of them were not familiar with their songs and could not even keep up with the pace when the others were singing. The researcher assumed that it is possible that some students did not learn from this assignment. According to the findings from the videos, most of the students presented positive learning outcomes such as showing seriousness, displaying a joyful attitude, and a showing a motivated manner towards this learning process.

\subsection{Lyrics}

Lyrics were the most important part of this assignment. This assignment required them to create English songs with the hopes of having students learn more words and improve listening or other English skills. Creating lyrics was the most direct way to train their English. Teacher could determine their learning achievements from the lyrics directly. Consequently, others could understand their own thought process when analyzing their lyrics. The words they use and the choice of songs could help reveal their innermost thoughts.

\subsubsection{Words}

Words in song lyrics are not usually difficult. There are still their uses of some unfamiliar words especially in translations. Take T1, T2 and T3 as examples. T1 was a translation work that translated a Chinese song entitled It's All Your Fault wherein students used "flimsy" and "frangibility". T2 translated another popular song titled The Brightest Star Shining upon Darkness where they used the word "embrace". T3 translated a Chinese song having abundant connotation as What is the Best Way for Me to Live on Earth wherein they used the word "prostrate". Students were not familiar with these words and these words were rarely incorporated into their composition or other translation assignments. Even in their responses, they admitted these words were new to them and translating songs helped them learn what these words meant.

Compared with translation, rifacimento from a lyric of originals was simpler. Take R1, R2 and R4 as examples. R1 combined Happy New Year and Two Tigers into one new song. They used the original melody and wrote new lyrics for it. For example, they sang "Many flowers open 
in spring /We love ice in hot summer /The most comfortable season is fall /Happy Christmas is in winter" in Happy New Year and "I love eating I love drinking / Do you know Do you know / Everything I love eat / Everything I love drink / Together Together" in Two Tigers. Despite the simple lyric, we could still find that they did this assignment carefully because of the amusing composition and creativity.

R4 combined Merry Christmas and Twinkle Twinkle Little Star into one song. They just changed several words in the base of original lyrics. They sang "we wish you a merry Christmas / we wish you a happy new year / we wish you a happy 2016 / and a happy holiday / a b c d e f $\mathrm{g} /$ twinkle twinkle little star / h I j k $1 \mathrm{~m} \mathrm{n}$ / how I wonder what you are". The lyric was so simple that they might just want to turn in the assignment and hope to get a passing grade.

The differences between translations and rifacimentos from original lyrics must be clearly defined. The direct reason was that when students wanted to translate Chinese to English, they would search for unfamiliar words in the dictionary. If they created a song by themselves, they would use familiar and simple words. In this way, the assumption is that translation might be more helpful for students to study new words. Based on the researcher's observations, this assignment might also develop students' other abilities, such as accomplishing a task, working with others, creating lyrics, songs, and words, doing research, brainstorming, developing their creativity, and appreciating the aesthetics of lyrics/songs/words in the performance of other groups, etc.

\subsection{The meaning of songs}

Translation method was the students' most selected choice for accomplishing this activity. They always chose popular songs which described events between lovers such as T1-It's All Your Fault. Rifacimento is even simpler. They always chose children's songs such as R4Merry Christmas and Twinkle Twinkle Little Star. R2, in particular, based on the song The Show and adapted its lyric. It portrays showed a student's worry about grammar class because her teacher said that she might fail her. However, she cheered up in the end and decided to work harder to pass the class. The lyric was as follows: "I'm just a little bit sad in the grammar class / because the teacher said I might fail this time / I don't know what's wrong / Can't do it alone I've tried / And I don't know why. / Slow it down / Take a breath / And I got faith to me myself / I can ask Google. I can ask my friends. / Nothing I'll be afraid / Get to class / Be in time and work harder than before." It was very amusing and had a sense of achievement.

To analyze the original songs they made had more significance. It is assumed that their thoughts become obvious in the works. Take $\mathrm{O} 1$ as an example. O1 was a work of a band, named Endless Night, Boundless Hollow.
In this song, they used a number of negative words such as crime, puzzles, pressures, hell, doom, rust, flee, wounds, lost and corrupt. They sang "Puzzles and pressures come in bound / Hell knows what is going on" as well as "Wounds, breaks, lost and corrupt / Does hope really exist". It showed that they had inner darkness but at the same time, they hoped for redemption. They wandered and were flimsy in their lives. The result of this activity could also assist university teachers to know about the students' inner world, and the content of the songs could help reveal students' psychological status. When negative words were frequently used in the song, it can help teachers become aware of some possible destructive emotion. As the pieces of original lyrics revealed those students' inner thoughts, the teachers could pay more attention to their emotions and counsel them when it is needed.

\subsection{Responses}

Compared with videos and lyrics, responses could help us analyze students' direct feelings and opinions of this activity, which we could observe from their submissions. Responses showed their behind-the-scenes stories. These responses could be roughly divided into two parts. One part was from team members and the other part was from individuals. The two parts showed the same pressure when they started the assignment. The most challenging step was to find rhymes. No matter if it was for originals or translations, it was difficult to find proper words to show their thoughts or the meaning of the base lyric. Singing it was also an issue. Team members must come together to practice singing it in chorus. They must learn it first and cooperate to sing together. Cooperation was a bottleneck for every team. Everyone's music talent was different; some learned it quickly while others had a slower pace. When they wanted to make an appointment to practice singing, schedules were not flexible. However, the two parts showed different processes and acquisitions while they were completing this assignment.

Responses of team members were similar. The first task for them was choosing a song. The first disagreement among team members also surfaced during this time. After, tasks were divided and assigned to different members when they started to create or translate a song. Many of them felt the challenge at first and disagreement existed throughout the entire process. Nonetheless, they felt the interest and got a sense of achievement. For most of them, it was the first time to do such work, so they thought it was fresh and some of them were grateful to the teacher to offer them this opportunity. Communication was the best way to resolve disagreements. Out from clear communication, they learned many different ideas and came up with fancy thoughts. The data showed that they learned from each other more than what they learned in class. 
The results showed that there were some students who completed the tasks by themselves. These students always had good musical accomplishments or even played musical instruments such as guitar or ukulele. They had many thoughts of their assignments and did not complain about creating or translating songs. $\mathrm{O} 2$ was an individual work. The creator said that she composed this song after watching the movie, Boyhood. She said, "This song wants to express that we will experience many things when we are growing up, including pity and fail. We can't choose it but we can choose how to face it." According to her response, we knew that when she created this song, she had sentimental attachment to her emotions and she showed it in the song successfully. T1 was also an individual work. The songwriter played the guitar. She said that when she recorded the video, she played the guitar so many times that her fingers swelled. She chose this song because of her prior interest to it and her passion to share it with her classmates. The objective of this activity was process-oriented where students needed to learn English by doing it. Although some of the students were worried about the difficulty of songwriting at first, the results demonstrated that the pressure was gone and the sense of achievement appeared.

\subsection{The Aesthetics of Songwriting}

The aesthetics are apparent in students' original songs. Take $\mathrm{O} 2$ as an example, "I miss the things of my part/ they seem will appear at a certain way/ I'm not surprised/ the innocent desire is destroyed/ time passed like/ blowing wind/ and we can't catch it/ 'what kind of man you wanna be?'/ I think I wanna be always me/ what the place it will take me to." She compared time to blowing wind, highlighting its unabiding nature. She also showed her confidence in the songwriting-when asked what kind of person she wants to be; she said that she wants to be herself. This song ended with "what the place it will take me to", revealing she was at sea likes many people at her age. All of the songs were included a slight feeling of melancholy as well as her selfdom, unfolding unique aesthetic.

\subsection{Fraud in Songwriting}

Most of students completed this assignment independently. However, there were still some students who tried to complete it by free riding. A group copied a song in its entirety from the web. When the teacher found out about it and asked them to do it again, they started to do it by themselves. The goal of action research is to improve processes. Action research is also beneficial in areas of teaching practice that need to be explored or settings in which continued improvement is the focus. Therefore, this kind of assignment should be inspected carefully to avoid plagiarism.

\section{Conclusions}

Many people proved that the use of English song is beneficial to student's English learning in many ways. The researcher testified that English songwriting also plays a significant role in a student's English learning progress. When they translated Chinese songs into English, they would search for unfamiliar words so that they could learn new vocabulary. When they adapted simple children songs, they had to find words that rhymed and learned how to pronounce it. In the process of completing this assignment, they learned from each other and learned how to express their thoughts in English.

However, they were not able to distinguish translation version and originals/creation. Just $14 \%$ of students wrote a new song. Other students submitted translated versions done in different ways but may be attributed to a lack of music or English language accomplishment. As for action research, the researcher clearly identified the problem, which was finding a new method of increasing students' learning motivation in learning English. However, at the second stage of developing the plan, it was considered a failure since the researched initially wanted that students would create a new song from scratch. It is a pity that this idealistic concept did not match the reality and so the researcher compromised with allowing students to translate instead of songwriting. The observation and reflection of this study can be used a reference for future study. It is suggested that in future studies, clear definitions or guidelines must be first established.

\section{REFERENCES}

[1] Sowa, P.A (2009). Understanding our learners and developing reflective practice: Conducting action research with English language learners. Teaching and Teacher Education, 25, 1026-1032.

[2] Milman, N. B. (2012). The Flipped Classroom Strategy What Is it and How Can it Best be Used? Distance learning, 9 (3), 85-87.

[3] McLaughlin, J. E., Roth, M.T., Glatt, D.M., Gharkholonarehe, N., Davidson, Griffin, C.A., Esserman, L.M., \& Mumper, R. J. (2014). The Flipped Classroom: A Course Redesign to Foster Learning and Engagement in a Health Professions School. Academic Medicine, 89 (2), 236-243.

[4] Bishop, J. L., \& Verleger, M.A. (2013). The Flipped Classroom: A Survey of the Research. $120^{\text {th }}$ ASEE annual conference \& exposition, American Society for Engineering Education, June 23-26, Atlanta. Retrieved from

https://www.asee.org/public/conferences/20/papers/6219/v iew

[5] Richards, J. (1969). Songs in Language Learning, TESOL Quarterly, 3(2), 161-174. 
[6] Si, J.F. \& Sun, M.L. (2007). The necessity and difficulty of translation of English song. Journal of HEZE Medical College, 19(4). Distance learning, Greenwich, 9(3) 85-87.

[7] 司景方 \& 孫美玲, (2007) 英文歌曲翻譯的必要和難 度。

[8] Lin,Z.Y. (2008). 林珍熒，(民九十七)。文學與音樂之課 程設計以流行音樂作為例, 談文學與音樂之關係高雄師 大學報: 人文與藝術類, 24 , 頁 $87-104$ 。

[9] Muñoz, C. (2014). Exploring young learners' foreign language learning awareness, Language Awareness, 23:1-2, 24-40; 2014

[10] Slavin, R, E., Harris, K, R., Graham, S., Urdan, T., Bus, Adriana G., Major, Sonya, \& Lee, S. H. (2012). Classroom applications of cooperative learning. APA educational psychology handbook, Vol 3: Application to learning and teaching. (pp. 359-378). Washington, DC, US: American Psychological Association, 8, 668.

[11] Ludke, K. M. (2016). Singing and arts activities in support of foreign language learning: an exploratory study. Innovation in Language Learning and Teaching: Retrieved from http://www.tandfonline.com/loi/rill20

[12] Xing, D. (2017). Exploring academic acculturation experiences of Chinese international students with low oral English proficiency A musically enhanced narrative inquiry. Queen's University; Kingston, Ontario, Canada. (Master Thesis) Retrieved from https://qspace.library.queensu.ca/bitstream/handle/1974/15 922/Xing_Deyu_201706_MED.pdf? sequence $=2$

[13] Chenug, C. (2001). The use of popular culture as a stimulus to motivate secondary students' English learning in Hong Kong. Retrieved from http://citeseerx.ist.psu.edu/viewdoc/download?doi=10.1.1. 474.6932\&rep=rep1\&type $=$ pdf

[14] Chuang, M. (2011). Effects of Songs and Picture Books on Students' Motivation in an EFL Classroom for the Elderly. Journal of Cheng Shiu University, 24, 105-114.

[15] Shao, 1. (2005). An Experiment on English-Songs in English Teaching. Journal of Hubei Institute of Education:123-125.

[16] Bertoldi, E. Kollar, J. \& Ricard, E. (1988). Learning how to learn English: from awareness to action. ELT Journal, 42(3) 157-166.

[17] Zhou, L. (2011). Application of English Songs to Senior School English Teaching of Vocabulary and Grammar. Central China Normal University; 2011: 41.

[18] Akbary, M. Shahriari, H. \& Fatemi, H. A. (2016). The value of song lyrics for teaching and learning English phrasal verbs: a corpus investigation of four music genres. Innovation in Language Learning and Teaching:1-13; 2016.

[19] Middleton, T. E. (2012). Music and Compound Words. The University of Toledo; A master thesis. Retrieved from http://utdr.utoledo.edu/cgi/viewcontent.cgi?article=1399\& context $=$ theses-dissertations
[20] Jia, H. (2012). The Application of English songs in English Listening Teaching of Senior High School: QUFU Normal University; 2012: 44.

[21] Jiang, M. (2015). Effects of English Songs on English Majors' Listening Teaching.: Qingdao University of Science \& Technology; 2015: 83.

[22] Duggan, T. J. (2003). Uses of Music in the High School English/Language Arts Classroom in South Dakota Teacher Perception and Practice. The University of South Dakota, America; 2003

[23] McClain, B.A., M.T. (2006). The Art of the English Teacher: The Beliefs and Practices of Three High School English Teachers Involved in the Arts. University of Virginia; 2006

[24] Chou, M. (2014) Assessing English vocabulary and enhancing young English as a Foreign Language (EFL) learners' motivation through games, songs, and stories. Education 3-13 42:284-297; 2014.

[25] Harbon, L. (2008). Chinese Students in a 'Sea' of Change: One Teacher's Discoveries about Chinese Students' Learning and Emotions through Use of Song. valuation \& Research in Education, 21:3, 214-234; 2008.

[26] Liu, N. Lin, C. K. \& Wiley, T. G. (2016). Learner Views on English and English Language Teaching in China. International Multilingual Research Journal, 10(2), $137-157 ; 2016$

[27] Liu, N. (2012). The Auxiliary Application of English Songs in Junior English Teaching.: Shanghai Normal University; 2012

[28] Wu, X. Z. (2011). Integration of Songs into the Teaching of Foreign Languages in a Cross-Culture Setting: Case of Using Songs in Chinese and English Teaching. East China Normal University; 2011: 206.

[29] Hand, D. M. (2015). An investigation of the creative process in songwriting in an undergraduate songwriting survey class. Boston University; 2015

[30] So, J. M. Y. (2012). Character development in music making: Understanding How Songwriting Can Develop Character. Queen's University; 2012

[31] Liao, M. Y. \& Campbell, P. S. (2014). An analysis of song-leading by kindergarten teachers in Taiwan and the USA. Music Education Research, 16(2), 144-161; 2014

[32] Merriam, S B. (1998). Qualitative Research and Case Study Applications in Education. Revised and Expanded from "Case Study Research in Education". [J]. British Educational Research Journal, 41(2):287-302

[33] Locke, K. (2002). Qualitative research and Evaluation Methods [J]. Nurse Education Today, 23(6):467-467.

[34] Ruhl, K. (2004). Qualitative Research Practice. A Guide for Social Science Students and Researchers [J]. Historical Social Research, 29(4 (110)):171-177. 